\title{
Where are all the synaesthetic chefs?
}

\author{
Charles Spence ${ }^{1,4^{*}}$, Jozef Youssef ${ }^{2}$ and Ophelia Deroy ${ }^{3}$
}

\begin{abstract}
With high-end chefs being increasingly considered as artists, gastronomy offers a new domain for our understanding of creativity. As several claims have been made about the link between synaesthesia and creativity, one would expect to find at least as many synaesthetes among chefs as among painters, composers, or writers-and perhaps even more- given the highly multisensory nature of the culinary arts. Here, we examine why synaesthesia is still underreported among creative chefs. Does the absence of such reports merely reflect the fact that synaesthesia is so overly common when it comes to the chemical senses to even merit attention, or on the contrary, that synaesthesia involving the chemical senses (i.e. smell, taste, or their composite, flavour) as either the "inducer" or "concurrent" is really rare? An alternative explanation, which we advance here, is that synaesthetic creativity, when expressed in edible form, may simply not be very tasty: As such, the very fact that the fruits of the artist's work are consumed may fundamentally distinguish the culinary arts from other inedible forms of art.
\end{abstract}

Keywords: Synaesthesia, Multisensory, Flavour, Art, Gastronomy, Creativity

\section{Introduction}

Chefs are increasingly being considered as the artists of the kitchen [1]. Even those who would tend to disagree with this label [2] nevertheless still accept high-end gastronomy as a truly creative endeavour. From the introduction of new ingredients, the refinement or elaboration of new culinary techniques and flavour combinations, through to the design of daring food presentations and complex meal narratives [3], modernist chefs are doing far more than merely pushing previous knowledge and skills to their limits. Instead, those at the top of their game are constantly creating new dining experiences. Because of its embodied and sensory nature, gastronomic creativity might, then, offer a great domain to understand human creativity.

Evidence collected over the last century or so suggests that synaesthesia may underlie much creative thinking and be over-represented among artists and art students [4-7]. Synaesthesia is the rare neurological condition in which people automatically experience a specific sensory or conceptual concurrent on perceiving or imagining a particular inducing stimulus [8-11]. While the prevalence of synaesthesia in the general population is estimated to be $6 \%$ maximum, self-reports of synaesthesia

\footnotetext{
* Correspondence: charles.spence@psy.ox.ac.uk

${ }^{1}$ Crossmodal Research Laboratory, Oxford University, Oxford, UK

${ }^{4}$ Department of Experimental Psychology, University of Oxford, Oxford OX1

3UD, UK

Full list of author information is available at the end of the article
}

among art students are about $23 \%$ [12]; more systematic tests conducted with 100 art students found that $7 \%$ saw letters in colours (a condition known as colourgrapheme synaesthesia) as compared to $2 \%$ in a random sample of the population. As the inducer-concurrent repertoire in synaesthesia tends to be highly idiosyncratic [13], the suggestion has sometimes been made that it might underlie the tendency to come up with original artistic combinations.

For well over a century now, the inspiration of many artists has been attributed, sometimes by themselves and sometimes by their late interpreters and biographers, to their synaesthesia: Just take painters such as Wassily Kandinsky or David Hockney, musicians and popular singers (from Alexander Scriabin to Jean Sibelius and Olivier Messaien, through to Jimi Hendrix, Pharrell Williams, and Lady $\mathrm{GaGa}$ ), and poets and writers (like Charles Baudelaire and Vladimir Nabokov $[14,15])$. As such, one might also have expected to find a surprisingly high number of synaesthetes among the most creative chefs. However, to the best of our knowledge as psychologist, chef, and philosopher interested in the condition, synaesthesia is very seldom reported by or among chefs. Furthermore, an internet search for "synaesthesia + chef" is no more conclusive, turning up virtually nothing of interest either. But is the absence of evidence

(c) 2015 Spence et al. Open Access This article is distributed under the terms of the Creative Commons Attribution 4.0 International License (http://creativecommons.org/licenses/by/4.0/), which permits unrestricted use, distribution, and reproduction in any medium, provided you give appropriate credit to the original author(s) and the source, provide a link to the Creative Commons license, and indicate if changes were made. The Creative Commons Public Domain Dedication waiver (http://creativecommons.org/publicdomain/zero/1.0/) applies to the data made available in this article, unless otherwise stated. 
evidence of absence? If not, where are all the synaesthetic chefs? The first goal of this paper is certainly to encourage the eventual synaesthetic chefs out there to report and describe their condition, or what they think of as unusual sensory blending guiding or interfering with their practice. Besides this call for testimony, we want to argue that a fresh look at culinary artistry is likely to help clarify the link between synaesthesia and creativity, as well as the differences and similarities between the culinary and other inedible art forms.

\section{Where are all the synaesthetic chefs?}

A few internationally renowned chefs, such as Homaro Cantu (of Moto fame) and Heston Blumenthal (of The Fat Duck among many other culinary ventures) have suggested that they might have had synaesthesia as a child [16]. However, few chefs report having the condition as a professional adult. The one chef whose writing might, at least at first glance, suggest synaesthesia, namely Paul Bertolli [17], turns out, on closer inspection, most probably not to have the condition (see [18], for a critical evaluation of this case). Our own internet-based searches have turned up only one other pastry chef with the condition (reported in [19]). If there are others, they certainly are not particularly vocal about their synaesthesia. Perhaps there are closet synaesthetes afraid of what their colleagues would tease them about in the heat of the kitchen. But given the rapid growth of multisensory experience design (see [20], for a review), and the related interest in synaesthetic design more generally [21, 22], one might have expected that more of the increasingly popular chefs would have started to come out of the woodwork. But they have not. So what exactly is going on here? Is there some deep-seated reason why synaesthesia and culinary artistry just do not mix?

The contrast here with other art forms is striking $[4,14]$. In the higher, or inedible arts, such as painting, music, literature, and poetry, many artists have claimed, or have been identified, to be synaesthetic. These writers, painters, musicians, and novelists regularly claim to have the condition, and what is more seems to utilize the unusual concurrents that they experience in their art. Some of the third-person attributions are often meant to make sense of some of the intriguing comments, which artists have made about their own work, and should be taken carefully (see [14], for some psychological detective work here). Many psychologists have nevertheless supported the link between synaesthesia and artistic creativity [5, 7]. The connection would appear to operate at two levels, with on the one hand, increased neural connectivity in synaesthesia being said to facilitate the creative association of ideas [23], and on the other, the synaesthetic associations experienced by synaesthetes, at least in the audiovisual case, being rated as pleasant by non-synaesthetes [24].
Too pervasive to be noticed, or too rare to emerge?

The first goal of the present piece is certainly to encourage more chefs to report on their possible synaesthesia and hence to get a better sense of the prevalence of this condition among those practising the culinary arts. But what do we expect chefs to report on? Food, and the chemical senses more specifically, is one domain where the tensions inherent to the definition of synaesthesia $[25,26]$ are perhaps most visible. If one takes synaesthesia to cover any experience of a conscious concurrent in an unstimulated modality, our tendency to confuse tastes and flavours [27], to describe odours using taste terms such as "sweet" for the aroma of vanilla, strawberry, or caramel (see [28], for a review), or even to feel acidity of our mouths when seeing a lemon might mean that we are all synaesthetes when it comes to food. ${ }^{1}$ If one follows this claim made, for instance, by Stevenson and Tomiczek [29], the existence of synaesthesia in the domain of flavour could simply be so ubiquitous that chefs might not be expected to have anything worth commenting on. On the other hand, if synaesthesia needs to be idiosyncratic and consistent over time, then the fact that taste-smell confusions are so common and that novel smells can acquire a particular taste association within just a few trials might mean that one would not want to count these broad tendencies as synaesthesia $[18,30]$.

With this more constraining definition of synaesthesia in hand, we would expect chefs to come out with specific cases where smells or tastes induce atypical experiences in other modalities (e.g. colours and sounds) or are systematically experienced when other non-chemical objects (e.g. shapes, words, and music) are presented. This, of course, assumes that the specific nature of the inducer-concurrent modalities determines the kinds of artistic activities that the synaesthete engages in-a claim which while on the surface plausible, cuts across the claim that it is a general enhanced connectivity that gives the creative boost $[23,31]$, and not a localized one. In all cases, then, chefs could be narrowly expected to present a higher prevalence of chemically related synaesthesia (already rare among the 60 and more forms of synaesthesia documented to date) or other kinds of synaesthesia (like colour-graphemes) than the 5-6\% documented in the general population [32].

\section{Synaesthetically inspired foods just do not taste that good}

We would, however, like to raise another hypothesis. Perhaps the reason why there might not be many synaesthetic high-end chefs out there might not be that there are fewer synaesthetes who attempt a career in the culinary arts in the first place, but that the dishes created by synaesthetes to capture their experiences simply just do not have a wider appeal: Dishes composed out of combinations dictated by idiosyncratic synaesthetic inspiration might not taste that good to the rest of the population. Just take the 
following recipe suggested by the synaesthete Sean Day as a case in point (taken from ([33], p. 2)).

\section{Light Cyan Blue}

Breast of chicken, one per serving

Vanilla ice cream (high quality real vanilla, not cheap artificial stuff)

Vanilla extract or, preferably, beans

Frozen orange juice concentrate

Brown sugar

Corn starch

The breast of chicken can be with or without bone, or may be half of a split chicken, including a leg, etc. - it really doesn't matter. What is important is that the skin and fat remain.

For the orange sauce, in a small pot, on low heat, warm up half a can of the orange juice concentrate, mixing in a teaspoon or two of brown sugar. The sauce should be sour, not sweetened with the brown sugar; the sugar is only there to add a touch of flavour, not sweetness. Add corn starch to the sauce to thicken it until it the viscosity is similar to thick molasses. Maintain on very low heat or otherwise keep it warm until serving.

Grill the chicken to preference. However, the skin should be crispy and the meat should remain very fatty; retain the fat, rather than draining, as needed.

The vanilla ice cream should be very cold and hard, such that it scoops into balls and will take longer to melt.

The chicken should be served hot (but not excessively so), right off the grill (with a little pouring of fat over it, if desired), topped immediately with one or two scoops of ice cream sprinkled with just a bit of vanilla, this all topped with enough orange sauce to cover part of the chicken and ice cream but not to drown it. Speed is of the essence here, as the idea is for the diner to be able to experience the contrasting heat of the chicken and the coldness of the ice cream for as long as possible before temperatures equalize.

Serve with a glass of light (wheat) beer flavoured with lemon, and a glass of red wine.

The above examples hopefully make clear the challenge. Day himself is under no illusion that the recipe he proposes will necessarily be appreciated by anyone other than himself. While chicken and orange do sometimes go together in recipes, chicken and ice cream does not intuitively sound like a promising culinary combination. Other examples of the difficulty of translating synaesthetic impressions through cooking would also include the famous synaesthete Michael, the inspiration for Richard Cytowic's book "The man who tasted shapes", having served what seems a perfectly decent chicken, who apologizes that "it's nearly spherical, [...] I can't serve this if it doesn't have points" ([33], pp. 392-393). In this case, the synaesthete experiences a pointy shape in his hand (the concurrent) when he smells the aroma of the chicken cooking (see also [19]).

The most important question to be asked, in our sense, is not so much how many chefs are synaesthetic, but the role that synaesthesia could play in culinary creativity. If idiosyncratic associations that are experienced by synaesthetes, at least in the audiovisual domain, tend to be more liked by non-synaesthetes [24], do we expect the same to be true for gastronomy? Perhaps the culinary arts, however inventive chefs are, are linked to more basic nutritional needs, familiarity, and hedonics. They continue to be bound to the subjective pleasantness of certain tastes or flavour combinations, and our distaste of others. This is part of the reason why some commentators have suggested that culinary endeavour, no matter how aesthetically pleasing the result, can never be considered a true art form $[2,34,35]$. Part of the resistance here about considering food even as a potential object of aesthetic appreciation is that since food is eaten, we cannot make a disinterested judgement about it. Hence, or so the Kantian argument goes, it cannot be an object of aesthetic appreciation, in the way that the disinterested contemplation of a landscape, a painting, or a piano concerto afford. Contrary to this line of argument, however, we would like to suggest that the lack of relevance of synaesthesia for gastronomy might show, not that it cannot be an art, but that its artistic value does not lie in the expression of originality and individuality. Its value consists on the contrary in a communal sharing of the beauty of foods and flavours (see Dinesen's Babette's Feast [36] for a literary rendition of this) and the playful reinterpretation of culinary codes and traditions.

\section{Conclusions}

Synaesthetic chefs at the top of their profession, either today, or at any time in the past, are noticeable by their absence from the literature or popular culture more generally (at least when one's attention is drawn to it). The absence is especially striking at the present time, given both the huge public exposure of many chefs these days $[37,38]$, not to mention the explosive growth of interest in multisensory dining and multisensory experience design [20, 39-42] and the seeming overrepresentation of synaesthetes in the other arts $([5,7]$; though see also [14]).

This absence raises different questions-the most obvious of which being what we expect culinary synaesthesia to be like. Are we looking for synaesthetic pairings involving taste and smell, whose incidence is very rare, idiosyncratic synaesthesia in other words, or are we ready to consider that everything having to do with flavour is synaesthetic? Trying to demonstrate that the incidence of synaesthesia in chefs is any different, statistically speaking, either from other groups of artists, or from the public at large, will need us to decide on what synaesthesia is (or rather, how exactly it should be defined). There is, though, a more fundamental question to be raised here: Why would we even expect chefs to be synaesthetes and to come up with flavour associations grounded in their idiosyncratic experience? Although creativity is synonymous with originality and individuality in certain domains, the understanding 
of creativity in other domains, gastronomy in particular, might lead us to revise this definition and consider the role that communal values and references play in it.

\section{Endnotes}

Here, it is important to distinguish synaesthesia from the rich olfactory mental imagery that some people, especially experts, have [43, 44]. It is an interesting question as to whether chefs have more pronounced imagery in the chemical senses than do non-experts. There is evidence that people can, under certain circumstances, imagine the consequences for taste of mixing unusual combinations of ingredients [45]. The question of whether such skills, which again, presumably rely on mental imagery are better in chefs is currently unknown [20].

\section{Competing interests}

The authors declare that they have no competing interests.

\section{Authors' contributions}

All of the authors contributed to the writing of this opinion piece, and all authors read and approved the final version of the manuscript.

\section{Acknowledgements}

CS and OD would like to acknowledge the AHRC Rethinking the Senses grant (AH/L007053/1).

\section{Author details}

${ }^{1}$ Crossmodal Research Laboratory, Oxford University, Oxford, UK. ${ }^{2}$ Kitchen Theory, London, UK. ${ }^{3}$ Centre for the Study of the Senses and Institute of Philosophy, School of Advanced Study, University of London, London, UK. ${ }^{4}$ Department of Experimental Psychology, University of Oxford, Oxford OX1 3UD, UK.

\section{Received: 27 August 2015 Accepted: 2 October 2015}

Published online: 13 October 2015

\section{References}

1. Dornenburg A, Page K. Culinary artistry. New York: John Wiley \& Sons; 1996.

2. Carey J. What good are the arts? London: Faber \& Faber; 2005.

3. Aduriz AL. Mugaritz: a natural science of cooking. New York: Phaidon; 2014.

4. Duffy PL. Blue cats and chartreuse kittens. New York: Henry Holt and Co; 2001

5. Mulvenna CM: Synaesthesia, the arts and creativity: a neurological connection. In J Bogousslavsky, MG Hennerici (Eds.), Neurological disorders in famous artists — part 2 (Basel, Karger). Front Neurol Neurosci 2007, 22:206-22.

6. Rothen N, Meier B. Higher prevalence of synaesthesia in art students. Perception. 2010;39:718-20.

7. Ward J, Thompson-Lake D, Ely R, Kaminski F. Synaesthesia, creativity and art: what is the link? Brit J Psychol. 2008;99:127-41.

8. Cytowic RE. Synaesthesia: a union of the senses. New York: Springer; 1989.

9. Cytowic RE. The man who tasted shapes. USA: GP Putnam's Sons; 1993.

10. Cytowic RE, Eagleman DM. Wednesday is indigo blue: discovering the brain of synesthesia. Cambridge: MIT Press; 2009.

11. Simner J, Hubbard EM. The Oxford handbook of synesthesia. Oxford: Oxford University Press; 2013.

12. Domino G. Synesthesia and creativity in fine arts students: an empirical look. Creativity Res J. 1989:2:17-29.

13. Grossenbacher PG, Lovelace CT. Mechanisms of synesthesia: cognitive and physiological constraints. Trends Cogn Sci. 2001;5:36-41.

14. Harrison J. Synaesthesia: the strangest thing. Oxford: Oxford University Press; 2001.

15. Massy-Beresford H: How we all could benefit from synaesthesia. The Guardian 2014, April 26th. Downloaded from http://www.theguardian.com/ science/2014/apr/27/benefit-synaesthesia-brain-injury-mental-decline on 25/ 08/2015.

16. Rossant J: (2007). Homaro Cantu: interview. Downloaded from http:// superchefblog.com/2012/02/07/homaro-cantu-interview/ on 24/08/2015.

17. Bertolli P. Cooking by hand. New York: Clarkson Potter; 2003.
18. Spence C, Deroy O. On the shapes of tastes and flavours. Petits Propos Culinaires. 2012;97:75-108.

19. Carlsen A: Some people really can taste the rainbow. The Salt 2013, March 18th. Downloaded from http://www.npr.org/sections/thesalt/ 2013/03/12/174132392/synesthetes-really-can-taste-the-rainbow on 24/08/2015

20. Spence C, Piqueras-Fiszman B. The perfect meal: the multisensory science of food and dining. Oxford: Wiley-Blackwell; 2014

21. Haverkamp M. Synesthetic design: handbook for a multisensory approach. Basel: Birkhäuser; 2014

22. Spinney L: Selling sensation: the new marketing territory. New Scientist 2013, 2934 (18th September). Downloaded from https:// www.newscientist.com/article/mg21929340-400-selling-sensation-the-newmarketing-territory/ on 25/08/2015.

23. Dailey A, Martindale C, Borkum J. Creativity, synesthesia and physiognomic perception. Creativity Res J. 1997;10:1-8.

24. Ward J, Moore S, Thompson-Lake D, Salih S, Beck B. The aesthetic appeal of auditory-visual synaesthetic perceptions in people without synaesthesia. Perception. 2008:13:1285-97.

25. Deroy O, Spence C. Weakening the case for 'weak synaesthesia': why crossmodal correspondences are not synaesthetic. Psych Bull Rev. 2013;20:643-64.

26. Simner J. Defining synaesthesia. Brit J Psychol. 2012;103:1-15.

27. Rozin P. "Taste-smell confusions" and the duality of the olfactory sense. Percept Psychophys. 1982;31:397-401.

28. Stevenson RJ, Boakes RA. Sweet and sour smells: learned synaesthesia between the senses of taste and smell. In: Calvert GA, Spence C, Stein BE, editors. The handbook of multisensory processing. Cambridge: MIT Press; 2004. p. 69-83.

29. Stevenson RJ, Tomiczek C. Olfactory-induced synesthesias: a review and model. Psych Bull. 2007;133:294-309.

30. Auvray M, Spence C. The multisensory perception of flavor. Conscious Cognit. 2008;17:1016-31.

31. Rouw R, Scholte HS. Increased structural connectivity in grapheme-color synesthesia. Nature Neurosci. 2007;10:792-7.

32. Day S. Some demographic and socio-cultural aspects of synesthesia. In: Robertson LC, Sagiv N, editors. Synesthesia: perspectives from cognitive neuroscience. New York: Oxford University Press; 2005. p. 11-33.

33. Day SA. The human sensoria and synaesthetic approach to cooking. Collapse. 2011:VIl:378-409.

34. Kant I. Critique of judgment. New York: Haffner; 1892/1951.

35. Monroe D. Can food be art? The problem of consumption. In: Allhoff F, Monroe D, editors. Food and philosophy. Oxford: Blackwell Publishing; 2007. p. 133-44.

36. Dinesen I. Babette's feast. In: Golden L, editor. A literary feast. New York: The Atlantic Monthly Press; 1993. p. 146-72.

37. Prince R: (2014). How we're fed 434 hours of TV cookery a week-but the more they show, the less we cook... DailyMail Online, 26th September. Downloaded from http://www.dailymail.co.uk/tvshowbiz/ article-2771553/How-fed-434-hours-TV-cookery-week-cook.html on 13/05/2015

38. Spence C, Okajima K, Cheok AD, Petit O, Michel C. Eating with our eyes: from visual hunger to digital satiation. Brain Cognit. 2015. doi: 10.1016/ j.bandc.2015.08.006.

39. Fleming A: quick bites: culinary synaesthesia, a feast for the senses. The Guardian 2015, February 20th. Downloaded from http://www.ft.com/cms/s/ 0/2be19458-b7bd-11e4-981d-00144feab7de.html on 24/08/2015.

40. Miller B: Artist invites public to taste colour in ten-day event with dancers and wine at The Oval. Culture 242015 [Retrieved from http:// www.culture24.org.uk/art/art516019-artist-invites-public-to-taste-colourin-ten-day-event\%20with-dancers-and-wine-at-the-oval].

41. Rhodes E. A synaesthetic dining experience. The Psychologist. 2015;28:090-9. Downloaded from http://thepsychologist.bps.org.uk/volume-28/ february-2015/synaesthetic-dining-experience?utm_source=Kitchen +Theory+Pop-up+mailing+list\&utm_campaign $=8 \mathrm{ac} 96 \mathrm{db} 6 \mathrm{ef}-$ Synaesthesia_final_dates4_28 2015\&utm medium=email\&utm _term=0_2f81822279-8ac96db6ef-189613837\&goal=0_2f818222798ac96db6ef-189613837 on 24/08/2015.

42. Brennan J. What's the taste of colours? Food and synaesthesia. 2014, June 3rd. Downloaded from https://www.finedininglovers.com/stories/ synaesthesia-food-event/ on 24/08/2015. 
43. Stevenson RJ, Case TI. Olfactory imagery: a review. Psychon Bull Rev. 2005;12:244-64.

44. Gilbert AN, Crouch M, Kemp SE. Olfactory and visual mental imagery. J Mental Imagery. 1998;22:137-46.

45. Barron HC, Dolan RJ, Behrens TEJ. Online evaluation of novel choices by simultaneous representation of multiple memories. Nature Neurosci. 2013;16:1492-8.

Submit your next manuscript to BioMed Central and take full advantage of:

- Convenient online submission

- Thorough peer review

- No space constraints or color figure charges

- Immediate publication on acceptance

- Inclusion in PubMed, CAS, Scopus and Google Scholar

- Research which is freely available for redistribution 